\title{
The Epidemiology and Clinical Profile of Tinea Pedis among Occlusive-Foot Wearing Policemen in Osogbo, Nigeria: A Case- Control Study
}

\author{
Olanrewaju Olayemi ${ }^{1}$, Adeolu Oladayo Akinboro ${ }^{2}$, Israel Gbenga \\ Michael $^{3}$, Sebastine Osaghe Oiwoh ${ }^{4}$, Olaniyi Emmanuel Onayemi ${ }^{5}$, \\ Olayinka Olasode ${ }^{5}$ \\ ${ }^{1}$ Dermatology Unit, Department of Internal Medicine, LAUTECH Teaching Hospital, \\ Osogbo, Osun State, Nigeria. \\ ${ }^{2}$ Dermatology Unit, Department of Internal Medicine, Ladoke Akintola University of \\ Technology and LAUTECH Teaching Hospital, Ogbomoso, Oyo State, Nigeria. \\ ${ }^{3}$ Dermatology and Venereology Unit, Department of Medicine, Bowen University \\ Teaching Hospital Ogbomoso, Oyo State, Nigeria. \\ ${ }^{4}$ Dermatology and Venereology Unit, Department of Internal Medicine, LAUTECH \\ Teaching Hospital, Ogbomoso, Oyo State, Nigeria . \\ ${ }^{5}$ Department of Dermatology and Venereology, Obafemi Awolowo University and \\ Obafemi Awolowo University Teaching Hospital Complex, Ile-Ife, Osun State, Nigeria
}

Corresponding Author Adeolu Oladayo Akinboro

Mobile:

$+2348136872240$

E mail: deolusteve111@yahoo. com

Key words:

Tinea pedis,

dermatophytes Epidemiology, Cutaneous Infection
Background and study aim : Tinea pedis is a common affliction of the feet that causes maceration, scaliness, pruritus, pain, and life quality impairment when untreated. TP affects individuals who wear occlusive footwear disproportionately. A case-control design was made to determine the frequency, risk factors, and implicated organisms among Policemen in Osogbo and compare with control.

Patients and methods: 250 policemen and 250 non-uniform wearing control were recruited. Relevant clinical data and physical examination were documented. TP was diagnosed clinically and confirmed by culture.

Results: The frequency of clinically $(12.4 \%$ vs. $8.4 \%)$ and mycologically $(9.6 \%$ vs. $6.8 \%)$ diagnosed TP were higher among Policemen than nonuniform wearing control. Interdigital TP was predominant, followed by the

\section{INTRODUCTION}

The dermatophytes are superficial fungal infections whose growth is mainly confined to the human skin's keratinous structures [1]. The Tinea pedis (TP), dermatophyte infection of the interdigital toe web spaces and the feet' skin, is caused by dermatophytes fungi [1,2]. Although some use the term athlete's foot to imply any form moccasin type. One to two interdigital spaces were frequently affected. Occlusive boots and socks wearing, prolonged use of socks, sharing of shower sponge, leather boot, sports participation, and farming $(\mathrm{p}<0.001)$ were significantly associated with TP in Policemen. Family history of atopy $(\mathrm{p}<0.001)$ and sharing socks $(\mathrm{p}=0.02)$ were significantly associated with TP in controls. In multivariate analysis, odds of mycological positive TP were significantly increased in male gender $(\mathrm{OR}=6.479,95 \% \mathrm{CI}=$ $1.49-28.26, \mathrm{p}=0.013)$, by farming or gardening $(\mathrm{OR}=2.622,95 \% \mathrm{CI}=2.54$ $15.11, \mathrm{p}=0.009)$ and excessive sweating in feet or palm $(\mathrm{OR}=6.197,95 \% \mathrm{CI}=0.75$ $3.55, \mathrm{p}<0.001)$.

Conclusion: Tinea pedis remains a disease of public health importance among occlusive wearers. Determinants of TP include male gender, farming, and excessive sweating in palms and feet.

of cleft space intertrigo, TP excludes bacteria, candida and nondermatophyte mould infections [1,2]. Tinea infections are highly prevalent in the tropics and subtropics because of conducive climatic conditions enhanced by environmental factors of heat, humidity and occlusive clothing $[1,2]$. Those susceptible to infection are infected after contact with an 
infected person, animal or contaminated soil. Dermatophytes have a high capability to digest keratin, which is utilized for their growth; they neither invade tissue nor cause systemic infection [1].

Tinea pedis is highly prevalent in military and paramilitary officers mainly because these groups wear occlusive boots quite often as part of their official uniforms, which creates a humid environment for dermatophyte growth [3-7]. Several studies have been conducted on TP as part of surveys for other dermatophytoses in Nigeria; few population-based studies exist among occlusive wearing uniform men specifically for TP and risk factors [3, 4]. Therefore, the present study is designed to evaluate TP's epidemiology and clinical profile among the Nigerian Policemen in Osogbo, a city in southwest Nigeria.

\section{PATIENTS AND METHODS}

A case-control study was conducted to determine the frequency, pattern, and risk factors of TP in Police Officers compared with non-uniform wearing control populations in Osogbo, Osun State, Nigeria. The systematic random sampling technique was applied to recruit 250 Policemen and an equal number of non-uniform wearing populations from the staff and students of Ladoke Akintola University of Technology (LAUTECH) Teaching Hospital, Osogbo. A comprehensive list of 800 Policemen serving in Osogbo was obtained from the police headquarters in Osogbo. This sample list was divided by the desired sample size to get approximately three (3) as the sampling interval. From the first three on the list, one number was selected by a simple random technique through the balloting method, and the subsequent respondents were gotten by adding 3 (sampling interval) to the first number. A similar design was followed to recruit the control population. The Research Ethics Committee of LAUTECH Teaching Hospital, Osogbo, Osun State approved the study.

Data was obtained using proforma that included area of service in the Police, demographic data such as age, sex, educational level, rank; years of service, history of the previous infection with TP and history of any other predisposing factor, e.g. excessive sweating in the palm and foot, walking barefooted, and participation in farming. We obtained history suggestive of atopy, history suggestive of peripheral vascular diseases such as cold feet, sports participation, shower, and sponge sharing. Data were obtained on the use of manicurist/pedicurist services and a history of diabetes mellitus. We enquired about wearing of occlusive boot, boot types, leather or rubber or both, the use of socks, the types of socks: nylon, cotton socks or both and the duration of occlusive wear.

A thorough physical examination was conducted during which the whole body and entire feet were examined in bright light, and a magnifying lens was used where necessary. The diagnosis of TP was suspected clinically and confirmed through culture. Skin scraping samples taken from the feet of individuals suspected of having TP using a sterile scalpel blade were put in a clean paper envelope and transported to the laboratory for analysis. Two drops of $10 \%$ potassium hydroxide $(\mathrm{KOH})$ were dropped on the specimen on a glass microscope slide and was heated gently to dissolve the scales while keeping the fungi intact. Slides were viewed under a medium power microscope and subsequently cultured on Sabouraud dextrose agar. Each dermatophyte was identified by its growth pattern on the agar medium.

The weight and height were obtained with the aid of a stadiometer. The body mass index (BMI) was calculated using the equation; weight $(\mathrm{kg}) /$ height $^{2}\left(\mathrm{~m}^{2}\right)$ and categorized according to: underweight when BMI is $<18.5 \mathrm{~kg} / \mathrm{m}^{2}$, normal, $\mathrm{BMI}=18.5-24.9 \mathrm{~kg} / \mathrm{m}^{2}$, overweight, $\mathrm{BMI}=25-$ $29.9 \mathrm{~kg} / \mathrm{m}^{2}$ and obese, BMI $\geq 30.0 \mathrm{~kg} / \mathrm{m}^{2}[8]$.

Skin scraping samples were taken from the feet of individuals suspected of having TP using a sterile scalpel blade into a blotting paper wrapped and subsequently transported to the laboratory for analysis using $10 \% \mathrm{KOH}$. Two drops of $10 \% \mathrm{KOH}$ were dropped on the specimen on a glass microscope slide. They were heated gently to dissolve skin cells while keeping the fungi intact, which was then viewed under medium power microscope and subsequently cultured on Sabouraud agar, and their growth pattern the agar medium identified each dermatophyte.

\section{Data Analysis}

Data were analyzed using version Statistical Package for the Social Sciences (SPSS) statistical software version 20 (SPSS 20, 
Chicago, IL, USA). Data were presented using descriptive statistics such as tables and bar charts. Categorical variables were expressed as proportions and percentages, while continuous variables were expressed as means and standard deviation. The TP's risk factors were analyzed by univariate (chi-square and fisher exact test) and multivariate logistic regression analysis. A probability of $\mathrm{p}<0.05$ was taken as statistically significant.

\section{RESULTS}

The study included 250 Policemen and 250 nonuniform wearing control population. Table 1 shows no significant difference in the mean age in years \pm SD of the Policemen and control (38.3 \pm 7.1 vs. $37.7 \pm 7.7, \mathrm{p}=0.355$ ). The non-uniform wearing control had mostly attained tertiary education $(86.8 \%$ vs $68.4 \%, \mathrm{p}<0.001)$ than the Policemen. The Policemen are known to be public servants, while most control populations were civil servants. Also, the subjects were significantly heavier $(78.5 \pm 12.8$ vs $65.2 \pm 12.0$, $\mathrm{p}<0.001)$, taller $(1.69 \pm 0.05$ vs $1.63 \pm 0.08$, $\rho<0.001)$ and had higher mean BMI $(27.3 \pm 4.0$ vs $24.3 \pm 4.2, \quad \rho<0.001)$ compared to the control population. Similarly, when grouped according to BMI, while the control group significantly had a healthy BMI, the subjects were significantly overweight and obese $(\mathrm{p}<0.001)$.

Figure 1 shows the number of years Policemen already spent in the Nigerian Police Force (NPF). About 119 (47.7\%) had spent 10-19 years in the force, 64(25.6\%) had spent 0-9 years, while $57(22.8 \%)$ had spent 20-29 years in the force, and only $10(4.0 \%)$ Policemen had spent above 30 years in service. Figure 2 shows the subjects' rank in the NPF. The majority, $114(45.6 \%)$, were in the Corporal cadre, followed by Inspectors, which accounted for 75 (30.0\%), Sergeants and Assistant Supritendents were 38 (15.2\%) and $23(9.2 \%)$ respectively.

Table 2 shows the risk factors for TP were compared between the Policemen and nonuniform wearing control populations. The subjects were significantly more likely to use occlusive boots $(100.0 \%$ vs $17.2 \%, \mathrm{p}<0.001)$, for an overall longer duration ( $\geq 10$ years), and longer hours per day ( $\geq 4$ hours) compared to the control population $(\mathrm{p}<0.001)$. Similarly, the Policemen were more likely to use leather boots than rubber boots or both $(77.6 \%$ vs. $48.8 \%, \&$
$13.2 \%$ vs $4.7 \% \quad \mathrm{p}<0.001)$. The boot sharing attitude was not different between the two groups. Also, the use of socks was significantly commoner among Policemen (100.0 vs. 39.6\%, $\mathrm{p}<0.001)$ compared to controls. Meanwhile, the control population were more likely to share socks $(1.6 \%$, vs $0.0 \% \mathrm{p}=0.02)$, use cotton socks instead of nylon $(67.2 \%$ vs $48.4 \%, \mathrm{p}<0.001)$ and have atopy history compared to the subjects (39.6\% vs $5.6 \%, \mathrm{p}<0.001)$. The Policemen were more likely to wear socks unchanged for at least one week $(25.2 \%$ vs. $19.0 \%, \mathrm{p}<0.001)$, participate in farming $(28.8 \%$ vs.8.8\%,p<0.001), sports (43.2\% vs.16.8\%,p<0.001), share shower sponge $(21.2 \%$ vs. $9.2 \%, \mathrm{p}<0.001)$ and have numbness of feet $(\mathrm{p}=0.01)$ compared to control population.

Table 3 shows the clinical and mycological frequency of TP and TP's clinical pattern in Policemen and the control population. There was no significant difference in the frequency of participants diagnosed clinically and those with CPTP between Policemen and control ( $p>0.05)$. The TP was clinically diagnosed in 31 (12.4\%) Policemen and 21 (8.4\%) of the control population. Similarly, CPTP was present in 24 (9.6\%) Policemen and $17(6.8 \%)$ of the control population. There was no significant difference in the morphological types of TP in both groups, $p>0.05$. The interdigital type of TP was the commonest in both groups (Fig $4 \& 5$ ). While the subjects had $15(6.0 \%)$ and $14(5.6 \%)$ TP on both the right and left foot, respectively, the control population had $10(4.0 \%)$ and $9(3.6 \%)$ on the right and left foot, respectively. The moccasin type (Fig 6) was next with the left foot's involvement only in both groups, $2(0.8 \%)$. The TP was more likely to affect one to two interdigital spaces of participants $(\mathrm{p}=0.028)$.

Figure 3 shows the respondents' Sabouraud's culture outcomes. The TP was significantly caused by T. mentagrophytes $(20.8 \%)$ and T. violaceus $(20.8 \%)$ among the subjects, while and T. verrucosum $(41.2 \%)$ and $\mathrm{E}$. floccosum (29.4\%) significantly caused TP among the control population, $\chi^{2}=17.069, \mathrm{df}=9, \mathrm{p}=0.047$. The culture-positive rate was $77.41 \%$ (24/31).

The CPTP was significantly present among the Inspectors compared to every other rank ( $\mathrm{p}=0.035)$, family history of atopy $(\mathrm{p}=0.005)$, farming or gardening $(\mathrm{p}=0.007)$ and male gender

Olayemi et al., Afro-Egypt J Infect Endem Dis 2021;11(1):78-87

https://aeji.journals.ekb.eg/

http://mis.zu.edu.eg/ajied/home.aspx 
( $\mathrm{p}=0.018$ ) were associated with CPTP in police officers. The presence of hyperhidrosis of hands and feet was associated with CPTP in both Policemen $(\mathrm{p}<0.001)$ and the control population $(\mathrm{p}=0.005)$, as shown in Table 4.

Table 5 shows logistic regression of predictors of occurrence of CPTP in policemen. The odds of having CPTP were significantly increased in male compared to female $(\mathrm{OR}=6.479,95 \% \mathrm{CI}=$ 1.49-28.26, P-value $=0.013)$, by farming or gardening $(\mathrm{OR}=2.622,95 \% \mathrm{CI}=2.54-15.11, \mathrm{P}$ value $=0.009)$ and excessive sweating in feet or palm $(\mathrm{OR}=6.197,95 \% \mathrm{CI}=0.75-3.55, \mathrm{P}-$ value $<0.001)$.

Table (1): Socio-demographic and Anthropometric Characteristics of Participants and Controls.

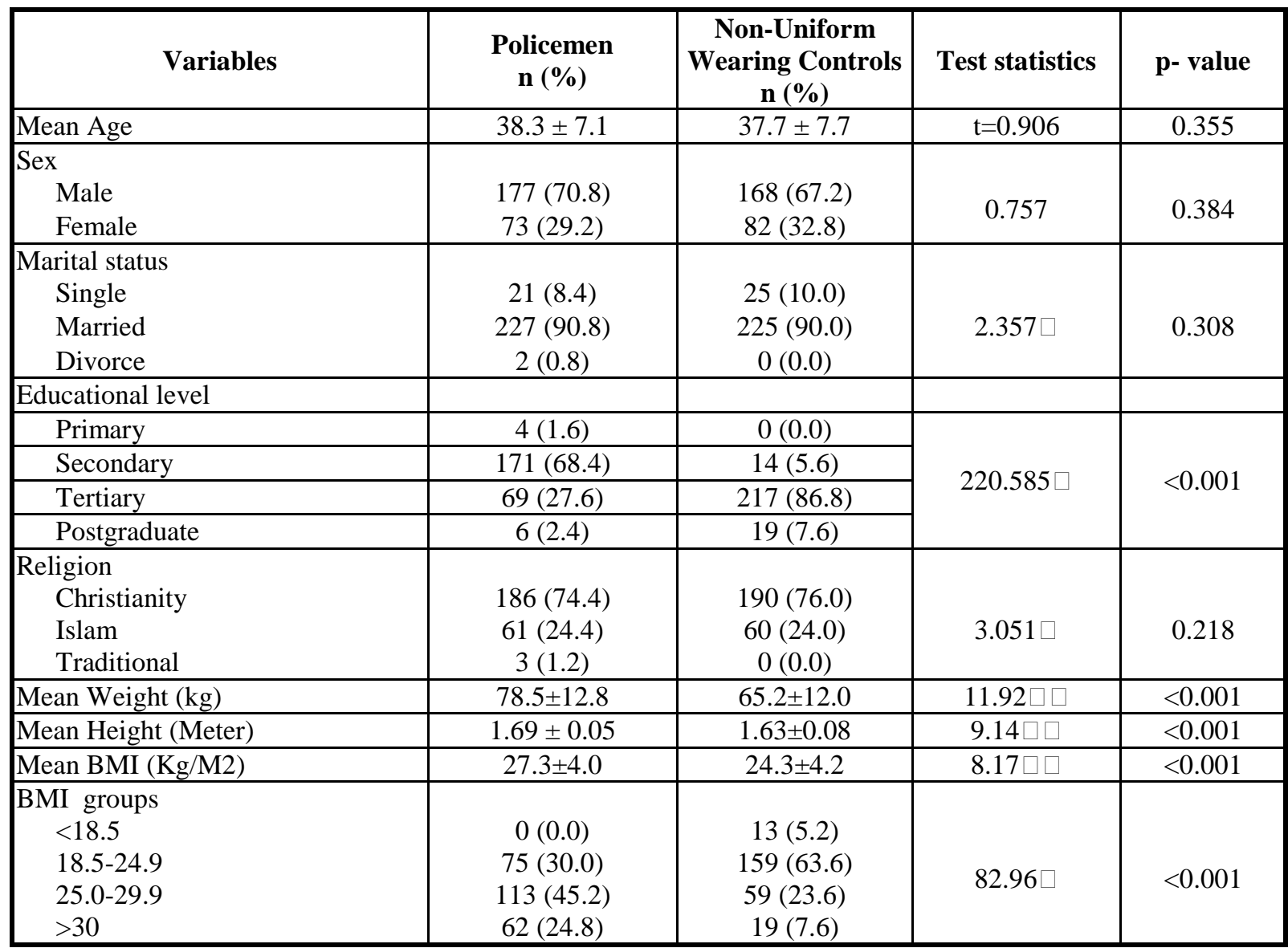

$\square \square=\mathrm{t}$ test,$\chi 2=$ Chi-square, $\square=$ Likelihood ratio chi-square, $\mathrm{t}=$ independent sample student-t-test 
Table (2): The risk factors for Tinea pedis in Policemen and Control Population.

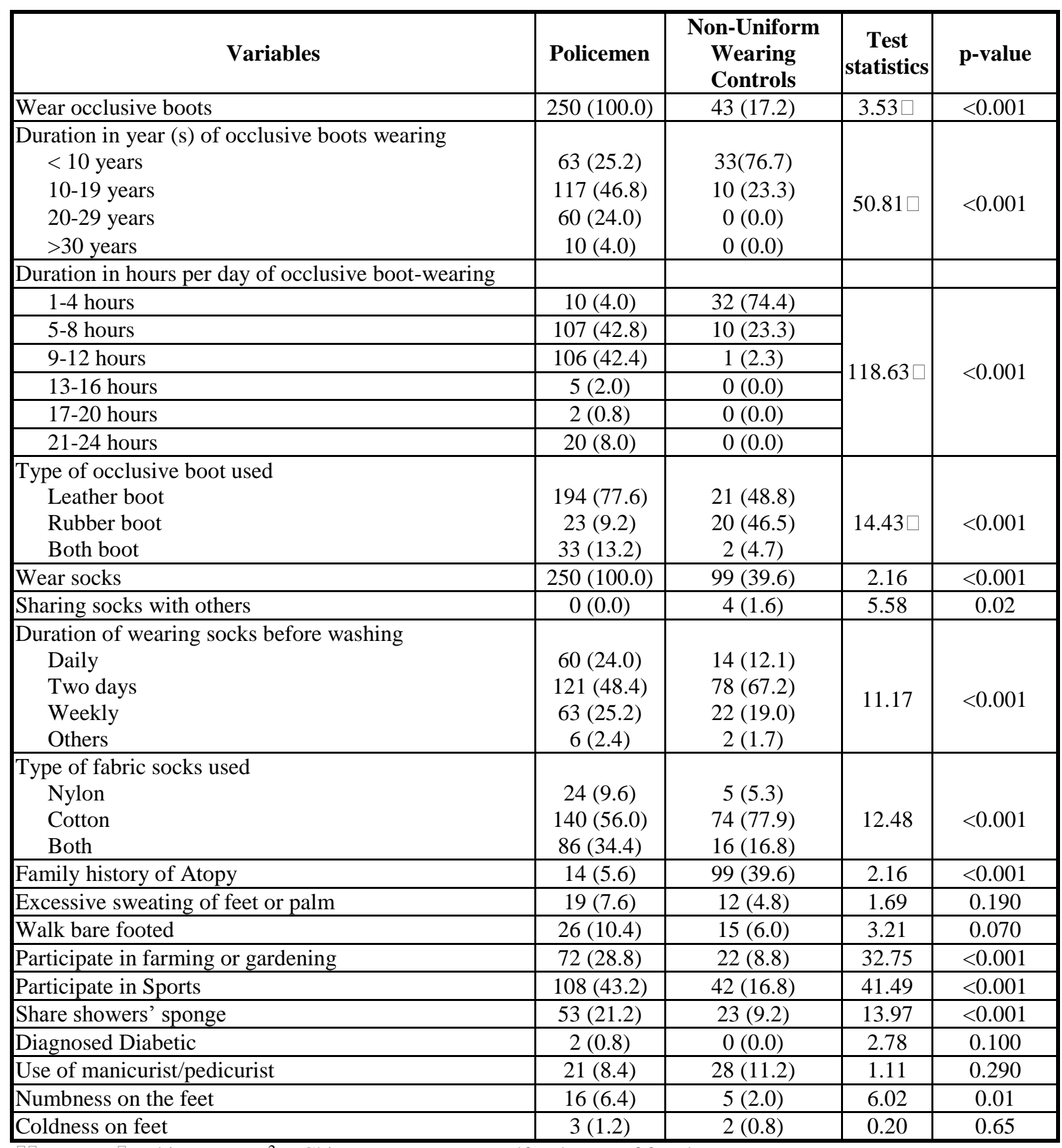

$=$ t test. ${ }^{\square}=$ chi square; $\mathrm{X}^{2}=$ Chi square test,

$\mathrm{df}=$ degree of freedom 
Table (3): Prevalence and Clinical Pattern of Tinea pedis in Policemen and Control Population.

\begin{tabular}{|c|c|c|c|c|}
\hline Variables & $\begin{array}{c}\text { Policemen (250) } \\
\text { n(\%) }\end{array}$ & $\begin{array}{c}\text { Non-Uniform Wearing } \\
\text { Controls (250) } \\
\text { n(\%) } \\
\end{array}$ & $\chi^{2}$ & $\begin{array}{c}\rho \\
\text { value }\end{array}$ \\
\hline Clinical diagnosis of Tinea Pedis & $31(12.4)$ & $21(8.4)$ & 2.146 & 0.143 \\
\hline KOH Positivity & $24(9.6)$ & $17(6.8)$ & 1.306 & 0.254 \\
\hline \multicolumn{5}{|l|}{ Pattern of Tinea Pedis } \\
\hline Interdigital (Right Foot) & $15(6.0)$ & $10(4.0)$ & 2.42 & 0.12 \\
\hline Interdigital (Left Foot) & $14(5.6)$ & $9(3.6)$ & 2.06 & 0.15 \\
\hline Moccasin form (Right Leg) & $2(0.8)$ & $2(0.8)$ & 2.78 & 0.10 \\
\hline $\begin{array}{l}\text { Interdigital feet spaces affected } \\
3 \text { interdigital spaces } \\
2 \text { interdigital spaces } \\
1 \text { interdigital space }\end{array}$ & $\begin{array}{c}3(9.7) \\
9(29.0) \\
19(61.3)\end{array}$ & $\begin{array}{c}1(4.8) \\
14(66.7) \\
6(28.6)\end{array}$ & 7.19 & 0.028 \\
\hline
\end{tabular}

$\chi^{2}$ - Chi-Square; $\quad$ n-number;

$\%$-percentages

Table (4): Culture Positive Tinea Pedis in relation to Participants and some clinical variables.

\begin{tabular}{|c|c|c|c|c|c|c|}
\hline \multirow[b]{2}{*}{ Variables } & \multicolumn{2}{|c|}{ Policemen } & \multirow[b]{2}{*}{$\rho$ value } & \multicolumn{2}{|c|}{$\begin{array}{c}\text { Non-Uniform } \\
\text { Wearing Controls } \\
\end{array}$} & \multirow[b]{2}{*}{$\rho$ value } \\
\hline & $\begin{array}{c}\text { Culture } \\
\text { Positive } \\
n=24 \\
\end{array}$ & $\begin{array}{c}\text { Culture } \\
\text { Negative } \\
n=226\end{array}$ & & $\begin{array}{c}\text { Culture } \\
\text { Positive } \\
n=17 \\
\end{array}$ & $\begin{array}{c}\text { Culture } \\
\text { Negative } \\
\mathbf{N}=233 \\
\end{array}$ & \\
\hline $\begin{array}{l}\text { Rank of Policemen } \\
\text { Corporal } \\
\text { Sergent } \\
\text { Inspector } \\
\text { Assistant Superintendent } \\
\end{array}$ & $\begin{aligned} & 9(37.5) \\
& 1(4.2) \\
& 13(54.2) \\
& 1(4.2) \\
&\end{aligned}$ & $\begin{array}{l}107(47.3) \\
37(16.4) \\
61(27.0) \\
21(9.0) \\
\end{array}$ & 0.035 & & & \\
\hline Clinical Variables & & & & & & \\
\hline Family history of atopy & $5(20.8)$ & $9(3.98)$ & 0.005 & & & \\
\hline Farrming & $13(54.16)$ & $59(26.11)$ & 0.007 & & & \\
\hline Sharing of shower sponge & $8(33.3)$ & $99(43.80)$ & 0.185 & & & \\
\hline Hyperhydrosis & $8(42.1)$ & $11(57.9)$ & $<0.001$ & $4(33.3)$ & $8(66.7)$ & 0.005 \\
\hline Manicure & $5(23.8)$ & $16(76.2)$ & 0.021 & $2(7.1)$ & $26(92.9)$ & 1.000 \\
\hline $\begin{array}{c}\text { Gender } \\
\text { Male } \\
\text { Female }\end{array}$ & $\begin{aligned} 22 & (12.4) \\
2 & (2.7)\end{aligned}$ & $\begin{array}{l}155(87.6) \\
71(97.3)\end{array}$ & 0.018 & $\begin{array}{c}14(8.3) \\
3(3.7)\end{array}$ & $\begin{array}{c}154(91.7) \\
79(96.3)\end{array}$ & 0.193 \\
\hline
\end{tabular}

Table (5): Binary Logistic Regression of risk factors for Mycological positivity of Tinea pedis.

\begin{tabular}{|c|c|c|c|}
\hline \multirow[t]{2}{*}{ Independent variables } & \multicolumn{3}{|c|}{ Outcome = Mycological Positivity of Tinea pedis } \\
\hline & Odds ratio & 95\% CI & p-value \\
\hline $\begin{array}{l}\text { Gender } \\
\text { Female } \\
\text { Male }\end{array}$ & $\begin{array}{c}\text { (Reference category) } \\
6.479\end{array}$ & $1.49-28.26$ & 0.013 \\
\hline $\begin{array}{l}\text { History of Atopy } \\
\text { No } \\
\text { Yes } \\
\end{array}$ & $\begin{array}{c}\text { Reference category } \\
3.109 \\
\end{array}$ & $1.12-8.60$ & 0.029 \\
\hline $\begin{array}{l}\text { Participate in farming or gardening } \\
\text { No } \\
\text { Yes }\end{array}$ & $\begin{array}{c}\text { (Reference category) } \\
2.622 \\
\end{array}$ & $2.54-15.11$ & 0.009 \\
\hline $\begin{array}{l}\text { Excessive sweating in feet or palm } \\
\text { No } \\
\text { Yes } \\
\end{array}$ & $\begin{array}{c}\text { (Reference category) } \\
6.197 \\
\end{array}$ & $0.75-3.55$ & $<0.001$ \\
\hline $\begin{array}{l}\text { History of manicure/ pedicure } \\
\text { No } \\
\text { Yes }\end{array}$ & $\begin{array}{c}\text { (Reference category) } \\
1.098\end{array}$ & $0.38-3.18$ & 0.862 \\
\hline
\end{tabular}

Olayemi et al., Afro-Egypt J Infect Endem Dis 2021;11(1):78-87

https://aeji.journals.ekb.eg/

http://mis.zu.edu.eg/ajied/home.aspx 
$\mathrm{CI}=$ Confidence interval

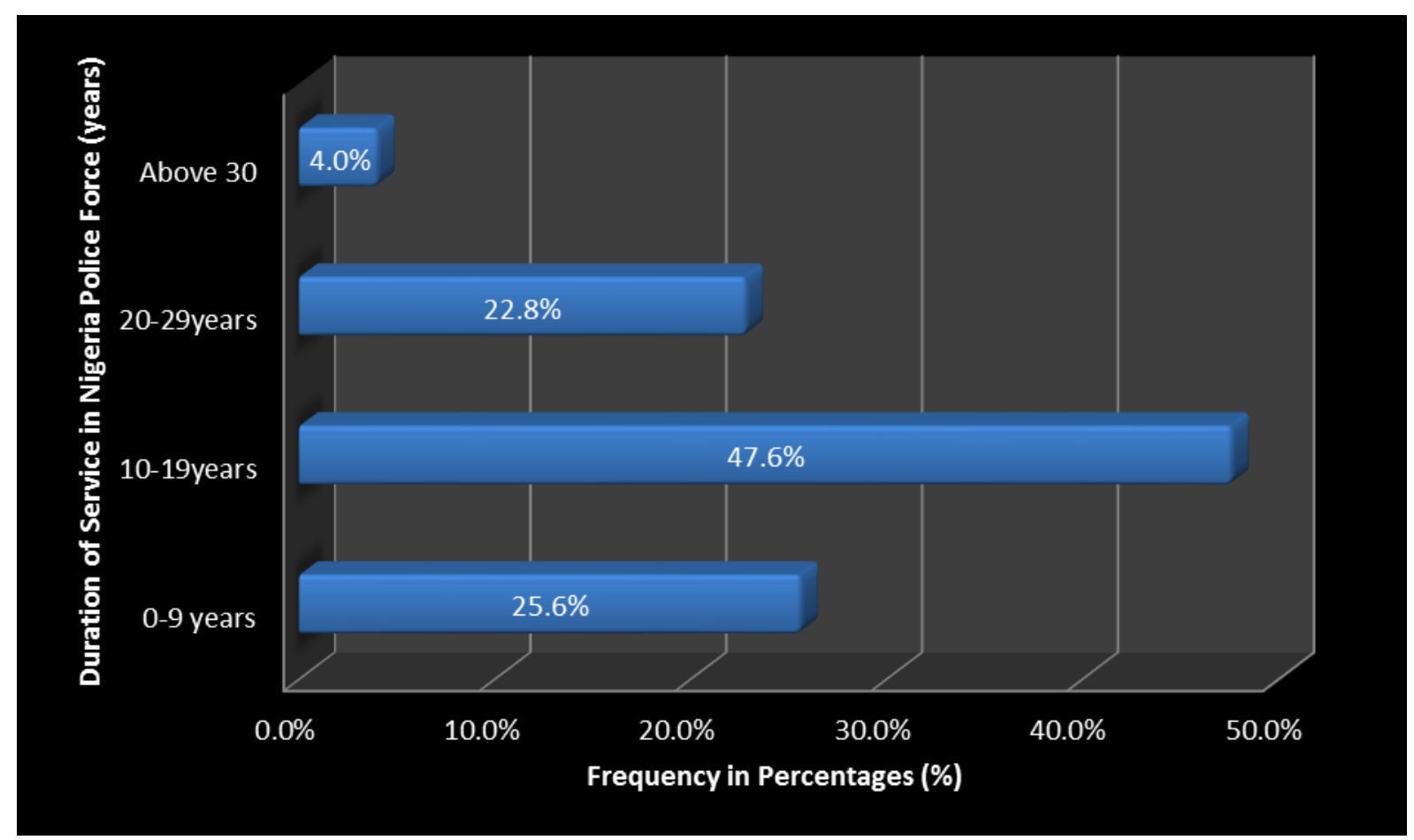

Figure (1): Police Men and Women Duration of Service in the Nigerian Police Force.

\section{DISCUSSION}

Tinea pedis is the foot's dermatophyte infection that is usually accompanied by nail infection $[\mathbf{1 , 2}]$. Tinea pedis occurs worldwide and is commonly found among military and paramilitary personnel, factory workers, and farmers who wear occlusive footwear over a long period [1-7]. In this study, TP's clinical and mycological frequency among Policemen was $31 / 250(12.4 \%)$ and $9.6 \%(24 / 250)$, respectively. These incidences were expectedly higher in Policemen than obtained among the non-uniform wearing control population, 21/250 (8.4\%) and $17 / 250(6.8 \%)$. The TP's clinical frequency found in the present study was low but fell within 9.7$61.0 \%$ documented in literature among uniform men [5-7]. Our clinical frequency was much higher than the prevalence of $0.5-2.8 \%$ documented among school children $[9,10]$ and $2.9 \%$ documented in a general Spanish and Mexican population [11,12]. This sharp difference in clinical frequency between the two populations showed the importance of occlusive footwear and related occupation, a predisposing factor for TP. In Nigeria, about four decades ago, Obasi et al.[3] found a higher clinical prevalence of $62.5 \%$ in a Nigerian Police Training College; possible factors responsible for this higher clinical prevalence could include the inclusion of non-dermatophyte moulds, candida species, and other possible inclusion diseases that have the potential to cause maceration and scaling in the toe webs.

The mycological frequency of TP found in this study was $9.6 \%$. This frequency fell within the lower limit of the documented prevalence of 4.0 $-45.3 \%[3, \mathbf{5}, \mathbf{9}, \mathbf{1 0}]$ in previous studies. The factors responsible for the prevalence variations could include sampling method, sample transportation and storage, culture medium used, and the microscopist experience. The frequency of culture-positive TP (CPTP) was higher among long-serving and middle-rank officers. The Police Inspectors who were middle-rank officers had a higher frequency of CPTP than those in lower ranks, which was in keeping with Marwan's study in which CPTP was associated with years in service but not the rank [6]. The factors that could explain this include a better socioeconomic package and education for the senior officers. The recruitment pattern could place educated officers in high rank and lowerranking officers engaged in more field operations than the senior officers exposing them to infecting dermatophytes.

The risk factors for TP in the Policemen in the present study were in keeping with previous works $[3,5,11,12]$ and were related to the

Olayemi et al., Afro-Egypt J Infect Endem Dis 2021;11(1):78-87

https://aeji.journals.ekb.eg/

http://mis.zu.edu.eg/ajied/home.aspx 
demands of occlusive footwear and related occupations. Studies have shown that high humidity creates a conducive environment for fungal growth, as seen in the occupations that wear occlusive footwear for a long time [5-7]. Other related factors included poor hygiene associated with prolonged use of cotton and nylon socks. Also, there has been evidence of the contagious spread of TP infection in many places: especially among factory workers and soldiers, especially during the Second World War. Apart from the occlusive footwear, essential risk factors associated with a higher TP incidence in Policemen included sharing public utilities such as sporting equipment and showers in Barracks as previously identified in other studies [5-7]. We observed a difference in the risk factors of TP between the Policemen and the control group. For the non-uniform wearing control population, the family history of atopy and transfer of infection through the sharing of dirty socks were significantly associated with TP.

In the present study, the interdigital type of $\mathrm{TP}$ was the most frequent clinical type found, followed by the moccasin type, same as the Muhammad et al. and other workers [13,14]. The vesiculobullous type was not documented.

The organisms responsible for TP in this study included Trichophyton mentagrophytes (20.8\%), Trichophyton violaceum (20.8\%), Trichophyton soudanense, Trichophyton verrucosum and Epidermophyton floccosum (12.5\%), Microsporum canis and Trichophyton tonsurans $(8.3 \%$ each) and Trichophyton schoenleni (4.2\%). The etiology of TP varies in studies [3-7, 9-13]. The genera Trichophyton was the most prevalent organism isolated in most studies [3-7, 9-13]. The predominant organisms in studies could be related to the source of infection, predominant organisms in the area, and the people's habits [15]. Perea et al. [15] also found Trichophyton rubrum (44.8\%) and Trichophyton mentagrophytes (44.8\%), followed by Epidermophyton floccosum $(7.0 \%)$ and $T$. tonsurans $(3.4 \%)$, were the organisms isolated from patients with TP in a general population. Like this study, certain studies have shown that $T$. mentagrophytes var. interdigitale was the usual organism associated with cases of asymptomatic or occult tinea pedis, while the Trichophyton rubrum was associated with symptomatic TP. Other authors did not confirm the same finding [16-18]. In comparison to many previous observations $[\mathbf{1 5 , 1 6 , 1 8 ]}$. T. rubrum was not isolated in the present study. Obasi et al. also did not isolate the T. rubrum in their study [3]. The reason for this difference is not apparent.

The predictors of TP in the present study included male gender, family history of atopy, farming/gardening, and hyperhidrosis of palms and feet. The odds of developing CPTP are increased by 6.5 in males. Sofia et al., in the general Spanish population, also found male gender as predictive of TP occurrence [19]. The predisposition could be unconnected with more men's engagement in jobs that necessitate the use of occlusive shoes and socks more than women. The odds of TP are increased by 6.0 for those with a history of hyperhidrosis of the palms and feet compared with their counterparts who do not have such history. Hyperhidrosis of the feet is an established risk factor for developing TP in the literature because excessive sweating in the foot creates a humid environment conducive for the growth of the dermatophytes, which can be further accentuated by occlusive footwear in the Policemen [20]. The police officers who participated in farming and their force job have their chances of developing CPTP increased by 2.6 than their counterparts who did not participate in farming. Participating in subsistence farming brought these officers in close contact with geophilic dermatophytes, primarily if protective shoes were not used while having contact with contaminated soil. The participants with atopy were three times more likely to have CPTP compared to those without atopy. Studies' outcomes were not uniform on the relationship between atopy and dermatophytosis. Escalante et al. [21] demonstrated that Trichophytosis was not more prevalent in atopic than in non-atopic subjects, and atopic diseases were not more frequent in culture-positive than in culture-negative patients. Contrariwise, studies have confirmed the association between chronic dermatophytosis and atopy. Atopy was viewed as a risk factor for chronic dermatophytosis. Other studies also linked dermatophytosis and specific allergic diseases such as asthma, rhinitis, urticarial and atopic dermatitis [22]. Treatment of dermatophytosis was associated with improvement of asthma after the administration of systemic antifungal [11].

The present study was not without some limitations. Firstly, Tinea unguium was not studied; therefore, association with TP cannot be defined. Secondly, the control population were

Olayemi et al., Afro-Egypt J Infect Endem Dis 2021;11(1):78-87

https://aeji.journals.ekb.eg/

http://mis.zu.edu.eg/ajied/home.aspx 
healthy individuals who were members of the University Teaching hospital community, and therefore caution should be exercised in the generalization of the findings. Thirdly, the documentation of risk factors of TP might have been limited by recall bias. Fourthly, we cannot claim a causal relationship between the risk factors and TP's existence been a case-control study. However, these limitations notwithstanding, compared with past studies in Nigeria, the present study recruited the largest number of participants with TP using a systematic random sampling method and stands to be a data source to compare with studies from similar settings.

\section{CONCLUSION}

In conclusion, the clinical and mycological frequency of TP was higher among Policemen than the control $31 / 250(12.4 \%)$ vs. $21 / 250$ $(8.4 \%)$ and $9.6 \%(24 / 250)$ vs. $17 / 250(6.8 \%)$. The interdigital TP was predominant, followed by the moccasin type, and one to two interdigital spaces were frequently affected. TP's risk factors in Policemen included wearing occlusive boots and socks, prolonged use of socks, sharing of 'shower sponge, leather boot, sports participation and farming. In the non-occlusive footwearing control, a family history of atopy and sharing of socks were significantly associated with TP. The predictors of the occurrence of CPTP included male gender, farming or gardening and excessive sweating in feet or palms. Individuals in occlusive footwear occupations should have regular feet examination by a Dermatologist.

Conflict of interest: None declared.

\section{Funding: None}

Ethical consideration: This study was conducted in conformity with the Declaration of Helsinki. The Research Ethics Committee of the LAUTECH Teaching Hospital, Osogbo, Nigeria, approved the study protocol.

\section{REFERENCES}

1. Hay RJ, Moore MK. Dermatophytosis, In Burns T, Breathnach S, Cox N, Griffith C (eds): Rook's Textbook of Dermatology, Vol 2, 7th ed. Oregon; Blackwell Science . 2004; 31: 19-31.

2. Margarido L C. Oral treatments for fungal infections of the skin of the foot. Sao Paulo Med J 2014; 132 (2): 127.
3. Obasi OE, Adeleke D, Clayton YM. Athlete's foot in boot-wearing policemen in Nigeria. Mycoses.1998; 31(5):268-270.

4. Akpata LE, Gugnani HC, Srivastava R, Utsalom SJ. Dermatomycoses among industrial workers in Gross River State, Nigeria.Mycoses.1992; 35: 371-74.

5. Cohen AD, Wolak A, Alkan M, Shalev R, Vardy DA. Prevalence of Tinea pedis in Israeli soldiers. Int J Dermatol. Dec 2005; 44 (12): 1002-1005.

6. Marwan A, Mohamad A, Waleed A. Prevalence of athlete's foot in Baharain Royal Navy, Baharain medical bulletin. 2013;(35).

7. Sezai S, Mustafa C. Dermatological infection in Turkish soldiers. Dermatological Sinica, 2011; 29:44-46.

8. Obesity and overweight. (Accessed November 10, 2020.

http://www.who.int.mediacentre/factsheets/fs311/ en/, index.html).

9. Djeridane A, Djeridane Y, Ammar-Khodja A. A clinicomycological study of fungal foot infections among Algerian military personnel. Clin Exp Dermatol. 2007; Jan 32 (1): 60-63.

10. Fekih E L, Belghite L, Trabels S. Epidemiological and etiological study of foot mycosis in Tunisia, Actas Dermosifliografa.2012; 6(103): 103520103524.

11. Weinstein A, Berman B. Topical treatment of common superficial Tinea infections. Am Fam Physician. 2002; 65:2095-2102.

12. Lopez-Martinez R, Manzano-Gayosso P, Hernandez-Hernandez F, Banzan-Mora E, Mendez-Tovar J. Dynamics of dermatophytosis frequency in Mexico: an analysis of 2084 cases. Med mycol. Nov 3 2009; 14:16-18.

13. Muhammad AL, Matthew S. Dermatology for the practicing allergist. Clinical and molecular allergy. 2004; 10:1476-1479.

14. Fitzpatrick T. B, Johnson R. A, Wolff K, Surmond D. Fungal infections of the skin and hair. In colour Atlas and synopsis of Clinical Dermatology Common and serious Disease. $4^{\text {th }}$ edition. Ed. Cooke D, English MR, Morriss JM. McGraw Hill Medical Publishing Division; 2001: 6-15.

15. Perea S, Ramos MJ, Garau M, Gonzalez A, Noriega AR, del Palacio A.Prevalence and risk factors of tinea unguium and tinea pedis in the general population in Spain. J Clin Microbiol 2000 Sep; 38(9):3226-3230.

16. Balci E, Gulgun M, Babacan O, Karaoglu A, Kesik V, Yesilkaya S, et al. Prevalence and risk factors of tinea capitis and tinea pedis in school children in Turkey. J Pak Med Assoc. 2014 May; 64 (5):514-518.

17. Triviño-Duran L, Torres-Rodriguez JM, MartinezRoig A, Cortina C, Belver V, Perez-Gonzalez M et al. Prevalence of tinea capitis and tinea pedis in Barcelona schoolchildren. Pediatr Infect Dis J. 2005; 24(2):137-141. 
18. Sakka N, Shemer A, Barzilai A, Farhi R, Daniel R. Occult tinea pedis in an Israeli population and predisposing factors for the acquisition of the disease. Int J Dermatol.2015; 54(2):146-149.

19. Sofia P, Maria JR, Morgorita GA, Antonia N. Prevalence and risk factor of Tinea unguium and Tinea pedis in general population in Spain. Clin Microbiol. 2000 Sept;38(9);3226-3230.

20. Tanvir A. M, Khalid M, Lugman S. Frequency of Tinea pedis in military recruits at Dera Ismail Pakistan. Gomal J Med Sci. 2013; 11:204-207.
21. Escalante MT, Sánchez-Borges M, Capriles-Hulett A, Belfort E, Di Biagio E, González-Aveledo L.Trichophyton-specific IgE in patients with dermatophytosis is not associated with aeroallergen sensitivity. J Allergy Clin Immunol. 2000; 105 (3):547-551.

22. Platts-Mills TA, Fiocco GP, Hayden ML, Guerrant JL, Pollart SM, Wilkins SR. Serum IgE antibodies to Trichophyton in patients with urticaria, angioedema, asthma, and rhinitis: development of a radioallergosorbent test. $J$ Allergy Clin Immunol. 1987; 79(1):40-45. 